\title{
16 Loneliness among informal caregivers aged 50+ in Europe
}

\footnotetext{
- Across Europe, caregivers aged 50+ feel lonelier than non-caregivers of the same age

- Caregivers' loneliness is exacerbated due to their increased family responsibilities

- The gap between caregivers' and non-caregivers' loneliness differs across countries

- The availability of formal care services lessens caregivers' loneliness, on the macro level
}

\subsection{Caregiving and loneliness in context}

This chapter analyses social exclusion in terms of the association between intensive caregiving and the feeling of loneliness. We examine whether caregivers of older people in need of long term care feel lonelier than persons who do not fulfil this role. We also consider the contextual features that mediate the relationship between care giving and loneliness.

Due to rising life expectancy and population aging in Europe, the number of older persons in need of long-term care is rising. Correspondingly, the demand for informal caregivers is also increasing (Colombo 2011). Providing long-term care is "a chronic stressor that places caregivers at risk for physical and emotional problems" (Pinquart \& Sörensen 2006: 33). The task is often associated with a reduction in well-being, physical and mental health, and life satisfaction (e.g. George \& Gwyther 1986). Caregiving also competes with other time demanding activities and can have a negative impact on the social inclusion of the caregivers (Shiovitz-Ezra \& Leitsch 2010).

There is currently a shortage in formal care arrangements, such as institutions and nurses, in many countries (Genet 2012). Moreover, the availability of informal caregivers is expected to decline in the future due to reduced family size, rising childlessness, fewer intergenerational households, rising divorce rates, increasing female labour force participation and potentially decreasing willingness to provide informal care (Pinquart \& Sörensen 2001). Thus, debates on adequate support policies for informal caregivers are ongoing in many European countries. 


\subsection{Hypotheses: links between caregiving and loneliness}

In the study reported in this chapter, we assess the association between caregiving and loneliness among people aged 50 and over in Europe. We consider the extent to which the relationship between caregiving and loneliness varies across countries, looking particularly at the role of formal care arrangements in relation to caregivers' loneliness. We hypothesise that caregivers experience more loneliness than non-caregivers. According to role strain theory, care provision leads to a time-based conflict between multiple roles (Greenhaus \& Beutell 1985). Caregiving is time and energy consuming and therefore caregivers are restricted in their personal, social and working life. As a result, caregivers experience time pressure and less time spent on activities that generally cause pleasure and joy. We argue that when role strain increases, the caregiver spends less time with social contacts and, thus, he or she feels lonelier.

Regarding country differences, we hypothesise that the association between caregiving and loneliness is mediated by the availability of formal care services. When formal care arrangements are available, the caregiver can make an informed choice as to whether to take over the care himself/herself or to get the needed care from a service provider. Research has shown that the tasks of informal caregiving are less intense when formal services are available (Brandt et al. 2009). Specifically, informal caregivers fulfil the less time consuming help tasks and the formal caregivers perform the more demanding nursing care tasks.

\subsection{Caregiving among Europeans 50+}

Data from SHARE Wave 5 (release 0 ) indicates the number of persons aged 50 and older who care for someone living in the same household (informal co-residential care, i.e. non-paid caregivers; single households were excluded). In total, 6.5 per cent of the sample (3,633 persons) provided informal care within the last year (total sample $=50,797$ ). Calculation of weighted estimation shows the following proportions of such informal caregivers in each country (Figure 16.1). As may be seen, the percentages vary from 3.5 per cent to 9.5 per cent.

Studies report that in Southern European countries the ratio of informal caregiving is higher than in other areas (e.g. Haberkern 2009). Our data, which additionally includes Eastern European countries, shows a North-West/South-East divide, (except for Belgium, which has a relatively high percentage of caregivers). 
That is to say, the countries in the South and East of Europe maintain higher percentages of informal caregivers than in the rest of Europe.

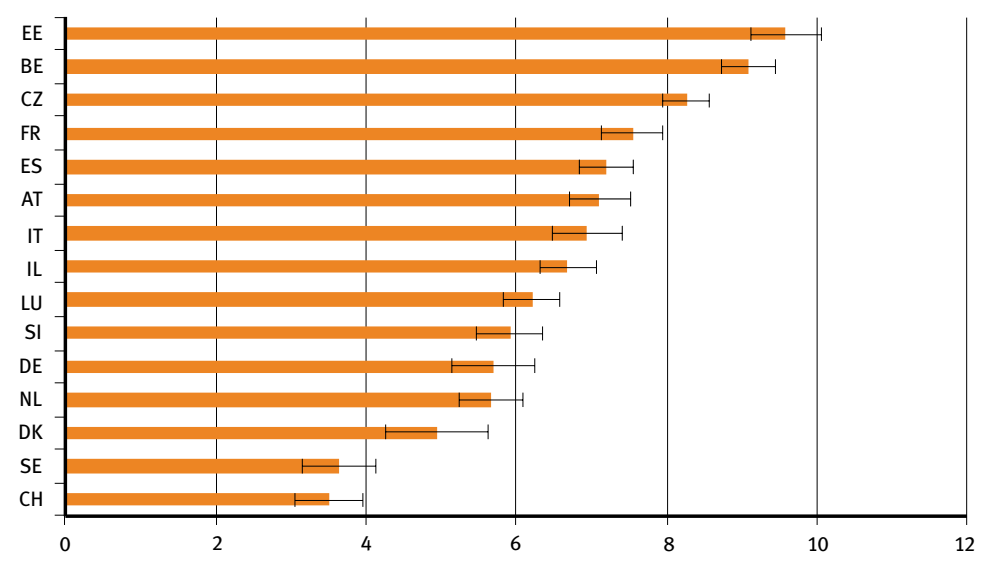

Figure 16.1: Percentage of informal caregivers among Europeans aged $50+$, by country (weighted) Notes: $\mathrm{N}=50,797$

Source: SHARE Wave 5 release 0

A majority of the informal caregivers report that they care for one person in the household (93.5\%), and 6.4 per cent care for two persons. Such informal care is given most often to the spouse or partner $(65 \%) .15$ per cent care for a parent or step-parent, and another 14 per cent care for a child, including grandchildren (among those who care for more than one person, as we did not consider respondents who care only for children). Another seven per cent care for other persons in the household.

\subsection{Loneliness among Europeans 50+}

Loneliness is the distress that results from discrepancies between ideal and perceived social relationships (Shiovitz-Ezra \& Leitsch 2010). Loneliness is linked with several negative outcomes, including depression (Beeson 2003), negative affect (Russell 1980) and social exclusion (see chapter 15 in this volume).

The SHARE Wave 5 data measures loneliness by means of the revised UCLA loneliness scale (Russell et al. 1980), using a shortened three-item version. The respondent was asked how much of the time he or she feels a lack of companionship, left out or isolated from others. The response options were "often", "some of the time" and "hardly ever or never". The distribution of loneliness by country 
is shown in Figure 15.1 in chapter 15. It shows that respondents in Northern European countries exhibit less loneliness than their counterparts in the Southern and Eastern SHARE countries (see also Sundström et al. 2009). Due to the skewness in the loneliness scale score distributions, the current analysis was based upon logarithmic transformations of the scores.

\subsection{Caregiving and loneliness}

\subsubsection{How is informal caregiving related with loneliness?}

We examined the association between informal caregiving and loneliness by means of linear regression analyses (four nested models) that controlled for the effect of other relevant variables as well. Table 16.1 shows the results of this multivariate procedure. In Model 1, loneliness was regressed on caregiving only. The results show a positive relation, indicating that caregivers are lonelier than non-caregivers. The beta coefficient of caregiving retained its statistical significance in the next two models, although the strength of the coefficient diminished somewhat as the additional respective variables were added to the analysis. It remained unaffected by the adding of the country variables (Model 4). These findings provide initial support for our first hypothesis.

Model 2 shows that the variable "family responsibilities" ("How often do you think family responsibilities prevent you from doing what you want to do" - never, rarely, sometimes, often) was positively linked with loneliness. That is, when respondents reported that they were burdened by family responsibilities more often, the likelihood of feeling lonely was also higher. This result further supports our first hypothesis, which is based upon role strain theory.

Model 3 added several control variables, and almost all of them were related to the loneliness outcome in the directions that have been found in previous research. The variable "urban area", which defines whether the respondent lived in an urban or rural area, was not related to loneliness. However, the regional context might affect the probability of receiving formal care services; the more urban the area, the higher the likelihood that formal care services are available. Praying as a proxy for religious beliefs showed a small but positive link with loneliness. Strong religious beliefs tend to go along with traditional family norms which, in turn, increase the probability of becoming a caregiver (Rossi \& Rossi 1990). 
Table 16.1: Caregiving and other correlates of loneliness (log)

\begin{tabular}{|c|c|c|c|c|}
\hline & Model 1 & Model 2 & Model 3 & Model 4 \\
\hline Caregiver & $\begin{array}{l}0.134^{\star \star \star} \\
(0.010)\end{array}$ & $\begin{array}{l}0.101^{\star \star \star} \\
(0.010)\end{array}$ & $\begin{array}{l}0.041^{\star \star \star} \\
(0.010)\end{array}$ & $\begin{array}{l}0.036^{\star \star \star} \\
(0.010)\end{array}$ \\
\hline Family responsibilities & & $\begin{array}{l}0.086^{\star \star \star} \\
(0.003)\end{array}$ & $\begin{array}{l}0.087^{\star \star \star} \\
(0.003)\end{array}$ & $\begin{array}{l}0.083^{\star \star \star} \\
(0.003)\end{array}$ \\
\hline Female & & & $\begin{array}{l}0.041^{\star \star \star} \\
(0.005)\end{array}$ & $\begin{array}{l}0.040^{\star \star \star} \\
(0.005)\end{array}$ \\
\hline Age (centered/1,000) & & & $\begin{array}{c}-1.070^{\star \star} \\
(0.360)\end{array}$ & $\begin{array}{c}-0.076^{\star \star} \\
(0.360)\end{array}$ \\
\hline Age (squared $/ 1,000$ ) & & & $\begin{array}{l}0.020^{\star \star \star} \\
(0.024)\end{array}$ & $\begin{array}{l}0.027^{\star \star \star} \\
(0.023)\end{array}$ \\
\hline Education (in years/100) & & & $\begin{array}{l}0.176^{\star *} \\
(0.058)\end{array}$ & $\begin{array}{c}-0.101^{\star} \\
(0.061)\end{array}$ \\
\hline Spouse/partner & & & $\begin{array}{l}-0.158^{\star \star \star} \\
(0.008)\end{array}$ & $\begin{array}{c}-0.152^{\star \star \star} \\
(0.008)\end{array}$ \\
\hline Working & & & $\begin{array}{l}-0.082^{\star \star \star} \\
(0.007)\end{array}$ & $\begin{array}{l}-0.074^{\star \star \star} \\
(0.007)\end{array}$ \\
\hline HH income (ppp, log) $)^{\mathrm{a}}$ & & & $\begin{array}{c}-0.012^{\star \star \star} \\
(0.003)\end{array}$ & $\begin{array}{c}-0.005^{\star \star} \\
(0.003)\end{array}$ \\
\hline HH size (2+) & & & $\begin{array}{c}-0.011^{\star \star} \\
(0.003)\end{array}$ & $\begin{array}{c}-0.014^{\star \star \star} \\
(0.003)\end{array}$ \\
\hline Poor self-rated health (5 cat.) & & & $\begin{array}{l}0.103^{* \star \star} \\
(0.003)\end{array}$ & $\begin{array}{l}0.088^{\star \star \star} \\
(0.003)\end{array}$ \\
\hline Chronic disease & & & $\begin{array}{l}0.033^{\star \star \star} \\
(0.006)\end{array}$ & $\begin{array}{l}0.043^{\star \star \star} \\
(0.006)\end{array}$ \\
\hline Urban area (5 cat.) & & & $\begin{array}{c}-0.002 \\
(0.002)\end{array}$ & $\begin{array}{c}-0.003 \\
(0.002)\end{array}$ \\
\hline Praying often ( 6 cat.) & & & $\begin{array}{l}0.009 \star \star \star \\
(0.002)\end{array}$ & $\begin{array}{l}0.009^{\star \star \star} \\
(0.002)\end{array}$ \\
\hline Constant & $\begin{array}{l}0.325^{\star \star \star} \\
(0.003)\end{array}$ & $\begin{array}{l}0.163^{\star \star \star} \\
(0.006)\end{array}$ & $\begin{array}{l}0.094^{\star \star \star} \\
(0.028)\end{array}$ & $\begin{array}{c}0.037 \\
(0.029)\end{array}$ \\
\hline $\mathrm{N}$ & 37,140 & 37,140 & 37,140 & 37,140 \\
\hline$R^{2}$ (adjusted) & 0.004 & 0.030 & 0.113 & 0.136 \\
\hline
\end{tabular}

Significance: * $p<0.1,{ }^{\star \star} p<0.05,{ }^{\star * \star} p<0.001$

Notes: Standard errors in parentheses, ${ }^{\text {a }}$ purchasing power parities, price level indices and real expenditures for ESA2010 aggregates [prc_ppp_ind].

Source: SHARE Wave 5 release 0, http://appsso.eurostat.ec.europa.eu/nui/show.do?dataset =prc_ppp_ind\&lang=en except Israel 
In Model 4 country dummies were included to control for country variation. The inclusion of country dummies raised the explained variance between Model 3 and Model 4 from 11.3 per cent to 13.6 per cent.

\subsubsection{To what extent does the relationship between informal caregiving and loneliness vary by country?}

Next, we show the country variation concerning the loneliness of caregivers and non-caregivers (Figure 16.2). The countries are ordered by the extent of the difference in loneliness between the caregivers and the non-caregivers. We see that caregivers experienced more loneliness than non-caregivers in all countries, except in Denmark. The difference was highest in Luxembourg, Slovenia and Sweden [but Luxembourg has the lowest number of caregivers in the sample $(\mathrm{N}=80)$, so that result should be treated with caution]. On the other hand, the difference in Denmark, Israel and Estonia was almost negligible. We can also see that the differences were not related to the absolute extent of loneliness in a country. Given that, what might explain the country differences in loneliness between caregivers and non-caregivers?

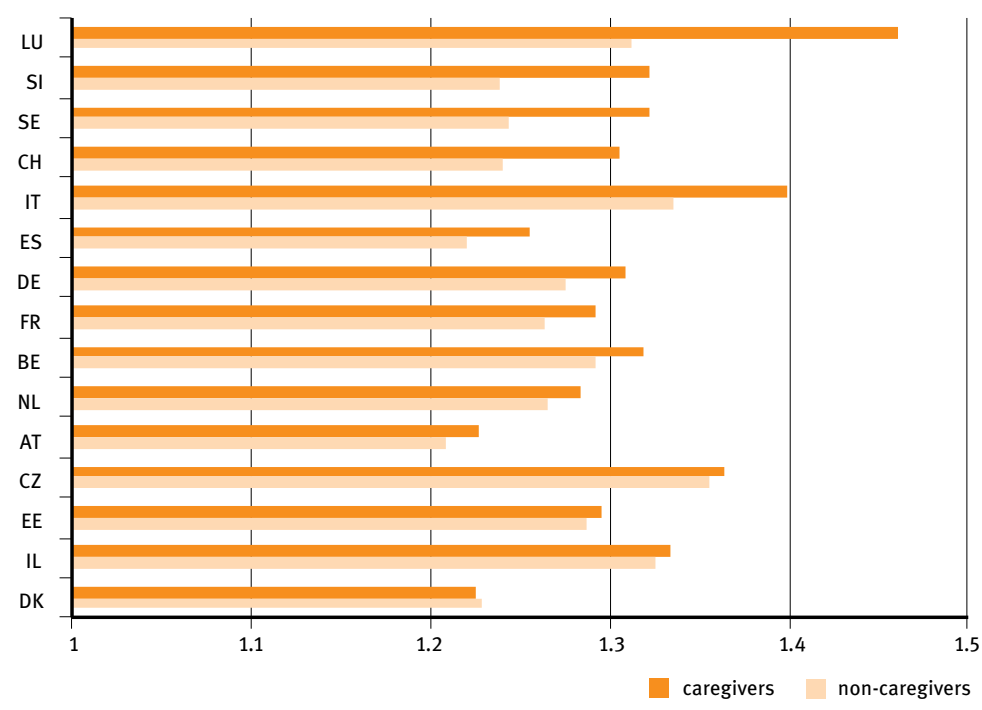

Figure 16.2: Loneliness of caregivers and non-caregivers, controlling for socio-demographic factors (see model 4 plus number of sisters alive)

Notes: $\mathrm{N}=32,228$

Source: SHARE Wave 5 release 0 


\subsubsection{The moderating role of formal care arrangements explaining caregivers' loneliness}

In the next stage of the analysis, we looked at a macro indicator on the country level to control for country-specific variation in the availability of formal care services. We took this step in order to test the second hypothesis, which states that the availability of formal care arrangements reduces the loneliness of caregivers. In order to make the formal care variable comparable across countries, we measured the formal care arrangements by means of an index that was based upon four indicators in 2009, or the closest year (OECD 2011) following the work of Verbakel (2014). These indicators were:

1) the proportion of the population aged 65 years and older receiving long-term care;

2) long-term care workers as a proportion of the population aged 65 and older;

3) long-term care beds in institutions and hospitals, per 1,000 persons aged 65 and older;

4) long-term care public expenditure (health and social components), as a proportion of the Gross Domestic Product (GDP).

Israel was excluded from this particular analysis due to missing macro data. These values displayed in Figure 16.3 represent the gap in loneliness between caregivers and non-caregivers.

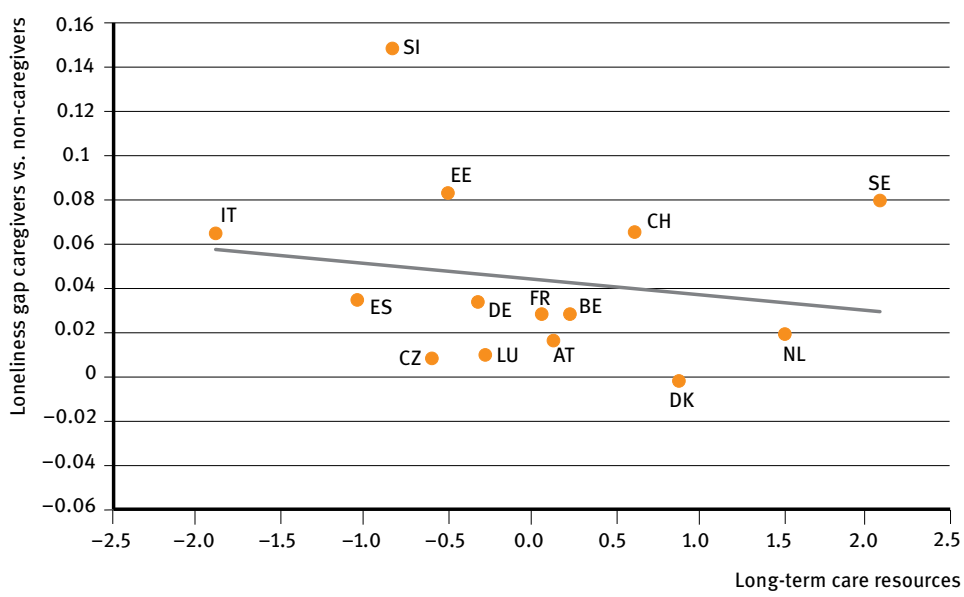

Figure 16.3: The relationship between formal care availability (standardised) and the countries' loneliness gap (log) between caregivers and non-caregivers, controlling for socio-demographic factors (see model 4 plus number of sisters alive)

Notes: $\mathrm{N}=31,359$

Source: SHARE Wave 5 release 0, OECD 2011 
Looking at the respective numbers in the figure, we see that the resources spent on formal care services were lowest in Italy, Spain and Slovenia and highest in Sweden, the Netherlands and Switzerland. In an additional linear regression analysis of loneliness in relation to formal care availability controlling for socio-demographic factors (not shown), the beta coefficient of the formal care index was significant (beta=-0.054; $\mathrm{p}<0.001$ ). That is, the increase in one standard unit of formal care availability reduced loneliness (log) by 0.054 standard units. In other words, formal care arrangements were associated with lower loneliness scores on a macro level.

Figure 16.3 shows a negative association between formal care availability and the loneliness gap; the more formal care was available, the smaller the gap between caregivers and non-caregivers. However, an additional analysis that employed an interaction term in the regression (not shown) was not significant. This means that caregivers from countries with generous formal care services did not differ in their loneliness scores from caregivers who resided in countries having fewer formal care services, all things considered. Based upon these results, we reject our second hypothesis.

\subsection{Caregiving and loneliness in Europe: another area of social exclusion?}

This chapter examined whether caregivers are lonelier than non-caregivers and if there are contextual features which contribute to this relationship. We found support for our first hypothesis which stated that caregivers experience more loneliness than non-caregivers, due to the reduced availability of social opportunities. Social opportunities were measured in our study as the extent to which family responsibilities prevented the respondent from doing what he or she wished to do. The family responsibilities variable serves as a mediator insofar as caregiving implies increasing family responsibilities which are correlated with greater reported loneliness. This relationship is not self-evident, since one could also argue that family responsibilities imply that people are surrounded by close contacts. It should be remembered, however, that loneliness is a subjective measure. It is not the number of people, per se, that makes people feel lonely or not, but the divergence between expectations and reality (Shiovitz-Ezra \& Leitsch 2010: 157).

Our second hypothesis stated that the possibility to make use of formal care arrangements reduces loneliness among caregivers. Although we saw some partial tendencies in the direction of the hypothesis, the data did not ultimately 
support this hypothesis in terms of statistical significance. We did find a negative relation between formal care service availability and loneliness, in general. That is, the more formal care services are available in a country, the smaller is the corresponding loneliness score in that country. But, this association does not differ significantly between caregivers and non-caregivers. It could be that the use of macro data on the country level, with only 14 observations, led to this insignificant interaction. Further analysis should use a multilevel design to include macro indicators on the regional or country level.

In order to get a more complete picture of the domain of informal caregiving, it is also recommended to look at the care that is given to someone who resides outside of the household. This would allow extending the field of inquiry to include the informal care of parents who do live in separate households. In addition, it would be helpful to investigate if there are differences in loneliness according to the type of relationship with the care recipient. For example, is care for one's own partner related to more loneliness than is care given to an older parent, or vice versa?

In sum, we have shown that loneliness among people aged 50 and older in Europe is mediated by the extent to which family responsibilities are considered to be burdensome, and that the amount of formal care services provided in a country seems to lessen loneliness among informal caregivers. Thus, formal care availability should be examined closely with respect to its potential to facilitate the role of informal caregivers and, in addition, in respect to its capacity to better promote their social inclusion.

\section{References}

Beeson, Rose (2003): "Loneliness and depression in spousal caregivers of those with Alzheimer's disease versus non-caregiving spouses”. In: Archives of Psychiatric Nursing 17, p. $135-143$.

Brandt, Martina, Haberkern, Klaus, Szydlik, Marc (2009): “Intergenerational help and care in Europe". In: European Sociological Review 25, p. 585-601.

Colombo, Francesca, Llena-Nozal, Ana, Mercier, Jérôme, Tjadens, Frits (2011): Help wanted? Providing and paying for long-term care. Paris: OECD.

George, Linda, Gwyther, Lisa (1986): "Caregiver well-being: a multidimensional examination of family caregivers of demented adults”. In: The Gerontologist 26, p. 253-259.

Greenhaus, Jeffrey, Beutell, Nicholas (1985): "Sources of conflict between work and family roles". In: The Academy of Management Review 10, p. 76-88.

Haberkern, Klaus (2009): Pflege in Europa. Familie und Wohlfahrtsstaat. Wiesbaden: VS Verlag für Sozialwissenschaften.

OECD (2011): Health at a glance 2011. OECD indicators. Paris: Organization of Economic Cooperation and Development. 
Pinquart, Martin, Sörensen, Silvia (2001): "Influences on loneliness in older adults: a metaanalysis". In: Basic and Applied Social Psychology 23, p. 245-266.

Pinquart Martin, Sörensen, Silvia (2006): “Gender differences in caregiver stressors, social resources, and health: an updated meta-analysis". In: The Journals of Gerontology. Series B, Psychological Sciences and Social Sciences 61, p. 33-45.

Rossi, Alice, Rossi, Peter (Ed.) (1990): Of human bonding. Parent-child relations across the life course. New York: A. de Gruyter.

Russell, Daniel, Peplau, Letitia, Cutrona, Carolyn (1980): “The revised UCLA Loneliness Scale, concurrent and discriminant validity evidence". In: Journal of Personality and Social Psychology 39, p. 472-480.

Shiovitz-Ezra, Sharon, Leitsch, Sara (2010): “The role of social relationships in predicting loneliness: the national social life, health, and aging project”. In: Social Work Research 34. No.3, p. 157-67.

Sundström, Gerdt, Fransson, Eleonor, Malmberg, Bo (2009): “Loneliness among older Europeans". In: European Journal of Ageing 6. No.4, p. 267-275.

Verbakel, Ellen (2014): "Informal caregiving and well-being in Europe: what can ease the negative consequences for caregivers?”. In: Journal of European Social Policy 24, p. 425-441. 